\title{
Discussões sobre Saúde e Doença: revisitando a obra adulta de Monteiro Lobato
}

Discussions about Health and IIlness: revisiting Monteiro Lobato's adult work

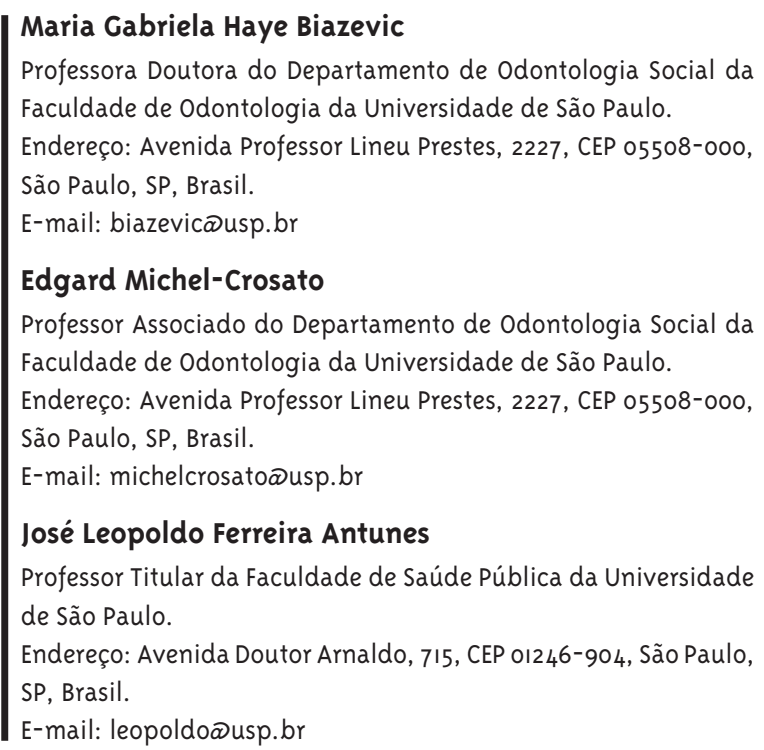

E-mail: leopoldoðusp.br

\begin{abstract}
Resumo
As opiniões de Monteiro Lobato a respeito dos temas saúde e doença não se esgotaram na discussão sobre a situação do Jeca Tatu; ele foi além, e em diversos trechos de sua obra adulta observam-se suas opiniões, seus relatos sobre a experiência de adoecer. 0 presente artigo resgata as concepções de saúde e doença observadas nos escritos de Monteiro Lobato. Por meio da análise de sua obra adulta, pudemos destacar opiniões, relatos sobre a experiência de adoecer de pessoas próximas e queridas, a possibilidade que a doença oferece de socializar as pessoas, o corporativismo médico, a atuação na Liga Pró-Saneamento, o paternalismo das práticas de saúde e a vulnerabilidade daqueles que possuem condição social desfavorável, além de outros tópicos, ora com traços de comicidade, ora com resignação e até com revolta. Assim, o presente estudo analisou a obra adulta do autor, discutindo trechos que tratam da saúde e da doença como experiência vivenciada nas primeiras décadas do século XX.
\end{abstract}

Palavras-chave: Medicina na literatura; Saúde; Doença; Corporações profissionais; Monteiro Lobato. 


\section{Abstract}

Monteiro Lobato's opinions with regard to the health and disease themes were not restricted to Jeca Tatu's condition; he went beyond, and his opinions and reports about the illness experience can be observed in several excerpts of his adult work. This paper highlights the health and illness conceptions observed in Monteiro Lobato's writings. Through the analysis of his adult work, we could learn about his opinions and reports on his beloved ones' experience of being sick, the possibility that the disease offers of socializing individuals, medical corporativism, his participation in the Pro-Sanitation League, some paternalistic health practices and the vulnerability of those with unfavorable social conditions, among other topics, in some occasions with comical characteristics, in others with resignation and even anger. Therefore, this study analyzed his adult work, discussing the excerpts that deal with health and illness experienced in the first decades of the $20^{\text {th }}$ century.

Keywords: Medicine in Literature; Health; Disease; Professional Corporations; Monteiro Lobato.

\section{Introdução}

Monteiro Lobato foi um autor de muito sucesso e controvérsias. Escreveu obras adultas e encantou o público infantil com as aventuras dos seus personagens no Sítio do Picapau Amarelo. Além disso, foi editor, e aqueceu o mercado editorial brasileiro a partir do final da década de 1910, quando os únicos livros a que a população brasileira tinha acesso eram as traduções dos "clássicos" (Cavalheiro, 1955). Suas cartas também são famosas, ao manter correspondência de 40 anos com o amigo Godofredo Rangel, além da trocada com familiares e Purezinha, sua esposa (Tin, 2007). Sua obra está repleta de comicidade (Duarte, 2006), artifício usado para discutir diversos temas de interesse da sociedade de sua época, bem como despertar a imaginação das crianças. Tratou de tópicos de política, economia, imprensa, editoriais e foi ícone de inúmeras gerações, principalmente por meio de sua obra infantil recheada de bom humor e informações didáticas (Lajolo e Ceccantini, 2008). Viveu em Taubaté, onde nasceu em 1882, em Areias-SP, onde foi Promotor Público logo após sua graduação na Faculdade de Direito do Largo São Francisco; morou em São Paulo, onde passou a maior parte de sua vida, e teve uma rápida passagem pelo Rio de Janeiro. Foi também adido comercial do Brasil em Nova Iorque; faleceu aos 66 anos de idade (Cavalheiro, 1955).

Sua obra tem sido objeto de inúmeros trabalhos, desde artigos, livros, dissertações e teses, e temse observado ser ela fonte inesgotável de estudo. Escrevia em linguagem acessível e discutia com clareza e objetividade assuntos de interesse da sociedade, além de temas infantis (Lajolo, 1993). Sua contribuição na área da Saúde Pública foi enorme, já que imortalizou o caboclo brasileiro como vítima de sua miséria. O Jeca Tatu, impaludado (portador de ancilostomíase, infecção de humanos e animais com ancilóstomas do gênero Ancylostoma), barrigudo, sem energia e com pouca vontade de trabalhar, era o protótipo de homem doente, atacado por verminoses que se eternizavam em sua condição socioeconômica desfavorável. E gerações e gerações de caboclos se seguiam sem que o problema do saneamento no Brasil fosse resolvido, eternizando a zona rural nacional como região de pobreza e descaso das autoridades (Lobato, 1961d). 
Porém, as opiniões de Monteiro Lobato a respeito dos temas saúde e doença não se esgotaram na discussão sobre a situação do Jeca Tatu; ele foi além, e em diversos trechos de sua obra adulta observamse suas opiniões, seus relatos sobre a experiência do adoecer de pessoas próximas e queridas, tais como seu filho Edgard, que morreu de tuberculose, a possibilidade que a doença oferece de socializar as pessoas, o corporativismo médico, o paternalismo das práticas de saúde e outros tópicos, ora com traços de comicidade, ora com resignação e até com revolta. Assim, o presente estudo analisou a obra adulta do autor, resgatando trechos que tratam da saúde e da doença como experiência vivenciada nas primeiras décadas do século XX. Além disso, discutimos também o material referente ao Jeca Tatu e à sua preocupação com a situação do caboclo brasileiro residente na zona rural, elucidando assim algumas novas facetas desse tão afamado escritor, possivelmente menos conhecidas do público. Não tivemos como objetivo esgotar suas opiniões sobre o tema, apenas levantamos material de interesse para aqueles que tiverem oportunidade de se aprofundar nessa faceta de sua obra.

Lobato tinha muito clara a importância da saúde para concretizar todos os outros projetos de vida. Em diversos trechos de suas cartas, ora destinadas ao seu pai (como pode ser observado no primeiro trecho abaixo transcrito), quando ainda era estudante, ora à sobrinha Gulnara (trechos seguintes), pode-se observar essa preocupação:

"Em primeiro lugar a sua saúde e a de todos daí." (Lobato, 1961h, p. 45)

"[[...]] Se está com o organismo abalado, o que tem a fazer é sarar, e o meio de sarar é o repouso sem preocupações na cabeça. Sare e depois conversaremos [...]. Bom. Chega de prosa. Mil cuidados para a saúde, que é o grande bem da vida. Sem ela, nada, absolutamente nada vale um caracol. Ninguém aprendeu isso melhor que eu, com as terríveis experiências da família." (Lobato, 1961i, p. 126-127)

"Adeus. Coragem, alegria, trabalho - e deixe correr o marfim. Tudo cicatriza, tudo se conserta - e tudo continua. Mas é preciso que haja saúde. Você viu por experiência própria a desgraça imensa que é falta de saúde. [...]"(Lobato, 1961i, p. 103)
Além do reconhecimento da importância de se ter saúde para o dia a dia, Lobato também associou saúde com beleza. Em carta destinada ao amigo Godofredo Rangel (Lobato, 1961g, p. 25), ao se referir a textos que tem lido ultimamente, destaca o modo de escrita do autor português Fialho de Almeida:

“[...] Que estilo! Bárbaro como um huno, belo como a saúde. [...]"

Com finalidade didática, os diversos trechos da obra adulta de Monteiro Lobato foram classificados em grandes temas, abrangendo praticamente a totalidade dos trechos analisados, conforme segue:

\section{Questões ligadas ao atendimento e à organização dos serviços de saúde}

- Dificuldades ligadas ao conhecimento e à linguagem técnico-científica

- Organização da atenção médica no país

- Críticas ao atendimento e às práticas médicas

\section{Perspectiva dos pacientes sobre doença, tratamen- to e cura}

- Diferentes significados do adoecer

- Visão dos pacientes sobre suas alternativas de cura

Utilizou-se como fonte de estudo a coleção Obras completas de Monteiro Lobato, $1^{\text {a }}$ série, com 17 volumes, publicada em 1961 pela Editora Brasiliense. Todo o material foi lido e foram transcritos todos os trechos que permitiram a discussão dos tópicos listados. O material selecionado foi analisado, e os trechos mais relevantes foram incluídos para a presente discussão. Do total de 1.106 capítulos, cartas, contos e comentários lidos em toda a coleção, 233 foram transcritos como material que, de alguma forma, fazia alusão a algum aspecto da discussão entre saúde e doença. Destes, selecionamos 25, que nos permitiram verificar a opinião do autor a respeito de temas como corporativismo médico, influência da [falta de] saúde no dia a dia, possibilidade de meios de socialização por meio da experiência de adoecer, alopatia e homeopatia, enfim, tais excertos mostram um pouco mais a faceta humanizada de Lobato ao longo de sua trajetória. Essa seleção teve finalidade apenas ilustrativa do pensamento do autor, e poderia ser modificada com a substituição de trechos, já que vários dos trechos transcritos expressavam as mesmas ideias gerais sublinhadas na presente análise. 
O critério de organização temática dos trechos coligidos teve como finalidade ordenar uma apresentação sistemática do pensamento do autor sobre os temas relacionados à saúde. No entanto, como qualquer classificação, deve ser considerada limitada quando se leva em conta a necessidade de abranger toda a diversidade temática e singularidade dos conceitos exarados na obra.

Diversas palavras tiveram sua grafia alterada para o vernáculo atual, facilitando assim a leitura, sem, no entanto, prejudicar o sentido e o entendimento dos trechos destacados.

\section{Questões ligadas ao Atendimento e à Organização dos Serviços de Saúde}

\section{Dificuldades ligadas ao conhecimento e à lingua- gem técnico-científica}

Em Urupês, sua obra adulta mais famosa (Cavalheiro, 1955), Lobato critica o linguajar de difícil compreensão que os médicos costumam utilizar, dificultando a compreensão dos leigos acerca de seus males. O conto "Pollice verso" trata do assunto, além de criticar o corporativismo médico nas cidades, em que toda a população fica a cargo de poucos desses profissionais que muitas vezes não resolvem a queixa de saúde do paciente. Discute-se também a questão da formação acadêmica nas universidades e do orgulho dos parentes que possuem um médico formado na família, que "fala difícil":

"Entre os médicos antigos de Itaoca, o doutor Inacinho gozava péssimo renome - se renome péssimo pode ser coisa de gozo.

- Uma bestinha! - dizia um. - Eu fico pasmado [...] é de saírem da Faculdade cavalgaduras daquele porte! É médico no diploma, na barbicha e no anel do dedo. Fora d'aí, que cavalo!

- E que topete! - acrescentava outro. - Presumido e pomadista como não há segundo. Não diz humores ou sífilis; é mal luético. Eu o que queria era pilhá-lo numa conferência, para escachar...

O pai, [[...]], esse babava-se d'orgulho. Filho médico, e ainda por cima destabocado e bem falante como aquele... Era de moer de inveja aos mais. Enlevava-o, sobretudo, aquele modo alcandorado de exprimirse.” (Lobato, 1961a, p. 91).

O autor, em carta ao amigo Godofredo Rangel em junho de 1917 (Lobato, 1961g, p. 139), fala do momento em que escreveu o conto: "Que tenho feito? Domingo, como amanhecesse chovendo, abanquei e pari "Pollice Verso", uma violenta mercurial contra os médicos. É a história dum facínora moderno, defendido por todas as leis e todos os preconceitos sociais, que mata um cliente rico para apresentar conta gorda no inventário. [...]"

Interessante destacar no trecho acima citado o comentário de Lobato, de que além da legislação vigente, o preconceito da sociedade pode proteger os profissionais legalmente habilitados, independentemente de sua conduta frente aos pacientes.

No conto "Era no Paraíso...", presente em Cidades Mortas, Lobato retoma o tema da dificuldade de compreensão da linguagem culta. 0 conto fala da criação do Paraíso, com todos os animais vivendo em harmonia em um mundo de paz, sem a existência de seres humanos. Nesse mundo ideal, existiria o Código da Sabedoria inato, não escrito, e não haveria nomes para as coisas.

"Este saber sem aprender receberia do homem o nome de Intuição, assim como o Código Ingênito receberia o nome de Instinto. Os futuros homens se caracterizariam pelo vezo de dar nome às coisas, gozando-se da fama de sábios os que com maior entorno e mais pomposamente as nomeassem. Grande doutor, o que tomasse o pulso a um doente, tirando do nariz os óculos de ouro: polinevrite metabólica; e grande mestre, o que apontasse o dedo para um grupo de estrelas e declarasse com voz firme: constelação de Centauro. Doença e estrelas, com ou sem nome, seguiriam o seu curso prefixo - mas nada de louvores ao medico que apenas dissesse: doença, ou ao mestre que humilde murmurasse: astros. Paga ou louvor não os teria o ignorante, isto é, o homem que não sabe nomes.” (Lobato, 1961b, p. 198)

Para fazer jus ao seu salário, há necessidade de codificar a prática das ciências, incluída aqui a médica, para que os leigos necessitem do "tradutor", intermediário que pode "desvendar" os mistérios do universo. No mesmo conto um macaco sofre queda, bate a cabeça e passa a se comportar de maneira 
muito diferente do restante dos habitantes desse paraíso...

"Desd'essa desastrada queda nunca mais funcionou normalmente o cérebro do pobre macaco. Doíamlhe os miolos, e ele queixava-se de vagados e de estranho mal-estar.

É que sofrera seríssima lesão.

Digo isto porque sou homem e sei dar nomes aos bois; homem ignorante, porém, não vou mais longe, nem ponho nome grego à lesão. Afirmo apenas que era lesão, certo de que me entendem os meus incontáveis colegas em ignorância nomenclativa.

Lesão grave, gravíssima, e de resultados imprevisíveis à própria preciência de Jeová." (Lobato, 1961b, p. 201)

A partir daí, inicia-se a Era da Inteligência, onde o deslumbramento das outras criaturas frente à mente privilegiada desse ser humano que se forma tornaria de menor importância todos os outros animais.

Assim celebrou, ironicamente, Lobato: "Viva o nome!" (Lobato, 1961b, p. 198).

\section{Organização da atenção médica no país}

Em "Fatia de vida" (Negrinha), observa-se a bondade de uma vizinha que avisa o posto médico sobre a presença de crianças doentes em uma residência pobre.

"Tinha em casa uma filha de dezoito anos, que trabalhava na costura; outra de dezesseis que a ajudava na lavagem; um filho de quinze, entregador de roupa, e mais uma netinha de seis anos, órfã.

A gripe apanhou-os a todos e a ela também. Mas a pobre criatura não soube disso, não o notou. Como perceber que estava doente, se suas faculdades eram poucas para atentar nos filhos? E lá sarou de pé, sem um remédio. E como ela também sarariam os filhos todos se...

\section{$[\ldots]$}

- ...se a caridade-sentimento não sobreviesse por intermédio do coração bondoso de uma vizinha. Esta vizinha, compadecida daquele angustioso transe, telefonou a um posto médico, narrando o caso e pedindo assistência. A ambulância veio justamente durante a ausência da Isaura que saíra a compras, e levou-lhe todos os filhos para o Hospital da Imigração.

Corriam boatos apavorantes a respeito desse hospital improvisado, onde - murmuravam - só se recebiam os pobres bem pobres e o tratamento era o que devia ser, porque pobre bem pobre não é bem gente. De modo que nada apavorava tanto o povinho miúdo como ir para a Imigração.

[...]

- ...uma alma caridosa apareceu e deu-lhe a informação pedida. Os filhos estavam lá, mais a netinha. A de dezesseis anos, porém, atacada de tifo.

- 'Tifo?! Exclamou, alanceada, a pobre mãe.

A alma caridosa enterrou mais fundo o punhal:

- 'Sim, tifo, e do bravo.

A mulher já não ouvia. De olhos esbugalhados, como fora de si, repetia a esmo a palavra tremenda - 'Tifo!' Conhecia-o muito bem. Fora a doença malvada que lhe arrebatara o marido.

- 'Quero vê-la, quero ver minha filha!...

- 'Impossível!

Isaura lutou, insistiu.

Inútil.

A porta fechou-se com chave e a pobre mulher se viu despejada na rua."

Na sequência, a mãe tenta ver os filhos, e é repetidamente impedida.

"A alma caridosa foi saber dos doentinhos e a triste mãe, embrulhada em seu xale humilde, ficou a um canto, esperando. Minutos depois reaparecia a alma caridosa.

- 'Olhe, sua filha morreu.

$[\ldots]$

- 'Morreu!... Mas qual delas?

- ‘Umas delas.

- 'Mas qual? Qual?...

$[\ldots]$

Da última vez que vi a pobre Isaura, disse-me ela, entre dois acessos de tosse:

- Tudo porque me levaram de casa os filhos. Se 
ficassem nada lhes teria acontecido. A nossa vizinha, tão boa, coitada, quis fazer o bem e fez a nossa desgraça. É um perigo ser muito bom..." (Lobato, 1961c, p. 238-243).

Entre 1890 e 1920, o terror tomou conta de São Paulo e de outras cidades, que tiveram de enfrentar surtos de febre amarela, de febre tifoide, de varíola, de peste bubônica e de gripe espanhola (Wissenbach, 1998). A gripe espanhola que atingiu São Paulo em 1918 e 1919 e atingiu grande parte das famílias paulistanas. Apesar dos dados oficiais terem contabilizado 12.386 vítimas no período no Estado (Bertolli Filho, 2003), sabe-se que tais dados estão subinformados (Bertolli Filho, 2003). Na cidade de São Paulo, chegou a atingir 116.777 pessoas (2/3 da população), deixando 5.331 mortos (Antunes e col., 1992). No círculo de pessoas que conviviam com Lobato, amigos, escritores e jornalistas, além de pessoas próximas à família, foram vítimas da tragédia.

"Se já sararam todos em tua casa, parabéns. Parabéns que ainda não posso receber porque tenho na cama três filhos e duas criadinhas. Só em minha mulher não deu a infernal gripe, mas deu no pobre Adalgiso. Acabo de vir do cemitério onde o enterramos. Morreu ontem às 7 da noite, dias depois de sair no $E s t a d o$ o seu último artigo, [...]

O que tem havido por aqui e no Rio é um rosário de horrores e tragédias. Aquelas infernais pestes da Idade Média deviam ser assim. Um furacão inopinado. Rajadas de morte. Só quem aguentou o lance num centro populoso como este, pode fazer ideia." (Lobato, 1961g, p. 184-5.)

Em Problema Vital, Lobato dedica os 15 capítulos a comentar e a denunciar a morosidade das autoridades na resolução dos problemas de saúde do povo brasileiro. Nesse livro, faz comentários sobre a situação da malária, febre amarela, esquistossomose, ancilostomose, doença de Chagas, tentando mostrar aos leitores o impacto econômico negativo que essa situação possui para a economia e sociedade do Brasil.

"Programa patriótico, e mais que patriótico, humano, só há um: sanear o Brasil.

$[\ldots]$

Reforma eleitoral só há uma: sanear o Brasil.
Fomento da produção só há um: sanear o Brasil.

Campanha cívica só há uma: sanear o Brasil.

Serviço obrigatório militar só há um: sanear o Brasil.

[...]

Se tencionamos subsistir como povo soberano, [...], o caminho é um só: sanear o Brasil.” (Lobato, 1961d, p. 244).

Encerra o livro com a tão afamada história do Jeca Tatu: “A Ressurreição", em que o caboclo pobre, que morava no mato e que passava os dias de cócoras se redime por meio do tratamento para a ancilostomose, que consistia em andar calçado, além do uso de medicação adequada. Com isso, a fazenda do Jeca passa a produzir como nunca, sendo alvo de inveja por parte dos vizinhos.

"Dava gosto ver as roças do Jeca. Comprou arados e bois, e não plantava nada sem primeiro afofar a terra. 0 resultado foi que os milhos vinham lindos e o feijão era uma beleza.

O italiano abria a boca, admirado, e confessava nunca ter visto roças assim.

E Jeca já não plantava rocinhas como antigamente. Só queria saber de roças grandes, cada vez maiores, que fizessem inveja no bairro." (Lobato, 1961d, p. 336).

Seus textos circularam no jornal $O$ Estado de São Paulo, e provavelmente alcançaram muitos leitores. Com essa abordagem, Lobato mostrou que o trabalhador rural, curado, poderia ser o motor para a transformação social do caboclo brasileiro (Lima, Hochman, 2000).

O processo de conscientização da população a respeito dos problemas de saúde pública do país, ao engajar-se na luta da Liga Pró-Saneamento, também trouxeram momentos engraçados. Em carta a Godofredo Rangel, ele se diverte com uma situação que lhe ocorrera:

“[...] A mim me favoreceu muito aquela campanha pró-saneamento que fiz pelo Estado [de São Paulo]. Popularizou a marca 'Monteiro Lobato'. O público imagina-me um médico sabidíssimo, e a semana passada tive um chamado telefônico altas horas da noite. 
- 'É o doutor Monteiro Lobato?'

- 'Sim.'

- 'Doutor, minha mulher está sentindo dores. Poderá vir atendê-la?'

Meu primeiro ímpeto foi ir e puxar para fora o filho daquele sujeito - depois contar o caso na rodinha. Mas a respeitabilidade venceu. 'Não sou médico parteiro, meu caro senhor' - 'Queira desculpar. Eu pensei que..." (Lobato, 1961g, p. 173-174).

\section{Críticas ao atendimento $e$ às práticas médicas}

Lobato trata com ironia os diferentes tratamentos com que os médicos costumam tratar seus pacientes, de acordo com a possibilidade de receber altos honorários pelo atendimento. Comenta que, dependendo da posição social do paciente, o médico o trata de maneira diferente. Foi o que ele relatou em carta de fevereiro de 1915, ao amigo de longas correspondências, Godofredo Rangel:

“[...] Indo ontem falar com um médico do Instituto Paulista, [...], recebeu-me ele de dois modos: o primeiro frio, indiferente o modo de receber aos que na vida não passam de números - mas depois que dei o meu nome, a cara do homem clareou." (Lobato, 1961g, p. 20).

Lobato, apesar de famoso e social e financeiramente bem estabelecido, não deixava de se indignar com essa situação de que seria tratado diferentemente de outro paciente, menos privilegiado, que procurasse pelos serviços do médico. Tanto na zona urbana quanto na rural, era constante a preocupação das famílias com a possibilidade de ter de recorrer a serviços médicos e à compra de produtos farmacêuticos, que muitas vezes acabavam por arruinar a economia das famílias (Telarolli Júnior, 1996).

Em outros trechos de sua obra, o autor se utiliza dessa mesma ironia para descrever as vantagens de ser doente em um meio social privilegiado. No conto "A policitemia de Dona Lindoca", o autor delicia os leitores com o relato de uma senhora da alta sociedade que possui doença de "nobres".

"Dona Lindoca sentia um certo orgulho da sua doença, cujo nome lhe soava bem aos ouvidos e fazia abrir a boca aos visitantes - policitemia... E como o marido e os demais lhe lisonjeassem a vaidade enaltecendo o chique das policitemias, acabou por considerar-se uma privilegiada.

\section{$[\ldots]$}

É doença de gente graúda, Lindoca. Este mundo!... Até em questão de doença as bonitas vão para os ricos e as feias vão para os pobres! Você, a Pilão Arcado e o Grouvion, com policitemia - e lá a minha costureirinha do Catete, sabe o que lhe deu? Tísica mesenterica..." (Lobato, 1961c, p. 181).

Outro dado interessante refere-se ao modelo de prática médica adotado no atendimento de pessoas da alta sociedade de São Paulo no início do século XX: os privilegiados podiam contar com visitas constantes do médico em suas residências ("O médico vinha vê-la amiúde, mostrando boa cara à doente [...]" (Lobato, 1961c, p. 183)), e convivia com as famílias como uma pessoa ilustre, não raro sendo convidado a compartilhar refeições com a família de seus pacientes. Porém, existiam doenças, como a tuberculose, que a literatura da época já identificava como “doença dos pobres" (Sheppard, 2001), dadas as suas características de associação com condições de vida insalubres nas moradias dos pacientes afetados.

Um tópico que merece destaque se refere à autoridade do médico sobre seus pacientes, independentemente da condição social destes últimos. 0 profissional é quem decidiria se a paciente estava curada ou não, sem considerar a opinião e/ou sintomatologia desta. "[...] Mais quem sabia da sua doença não era ela e sim o médico. De modo que enquanto ele não lhe desse alta, teria de continuar nas delícias daquele tratamento." (Lobato, 1961c, p. 184).

Lobato interessava-se pelas ações de saneamento do Brasil. Em diversos escritos, observam-se comentários a respeito dos trabalhos de Osvaldo Cruz em Manguinhos, de seu discípulo Artur Neiva, e de Belisário Pena, por sua atuação em todo o país. Ao publicar relatório sobre a expedição médicocientífica realizada em 1912 pelo Brasil, trouxeram à tona a situação insalubre, atrasada e improdutiva da população (Lima e Hochman, 200o).

Sobre os feitos de Belisário Pena, que combateu inicialmente a varíola e a febre amarela no Rio de Janeiro e que passou a vida em viagens para conhecer e intervir nas condições de saneamento da população brasileira de norte a sul do país (Thielen e Santos, 
2002), Lobato escreveu:

"Revelou ao país o seu estado de doença. Demonstrou que há no Brasil 70\% de criaturas bichadas pela verminose. Provou que em trinta milhões de criaturas há mais de vinte milhões de inutilizados, sombras de gente, cadáveres vivos, mero pasto de bichos gordos e satisfeitos." (Lobato, 1961d, p. 116).

Acabou por aceitar convite de Artur Neiva, Chefe do Serviço Sanitário de São Paulo, para acompanhálo em uma excursão ao Vale do Ribeira, região sul do Estado.

"Uma anedota documental. Em excursão a Iguape, a ver com seus olhos como iam os trabalhos de combate à opilação e à malária lá iniciados, convidounos [Artur Neiva] para companheiros de viagem. Fomos. Viagem longa, de um dia inteiro, começada em trem e concluída em lancha pela Ribeira abaixo. Chegamos ao escurecer. Depois do jantar, enquanto os outros se ajeitavam para o descanso ou no bilhar batiam bola para desentorpecimento dos músculos, vi parar à porta um camarada com três matungos arreados. Neiva convidou-me a acompanhá-lo e lá fui, nove da noite, sem saber ao quê. Penetramos na mata, alguns quilômetros fora da cidade. Vi-o apear-se e acender a lanterna elétrica, e correr a luz pelo couro do cavalo em procura de anofelinas que incontinenti acudiram àquele inesperado banquete. Uma hora passou ele assim, caçando mosquitos, e dissertando sobre as particularidades de cada espécie. 0 caso era este: havia naquelas bandas um foco malárico resistente a todos os trabalhos da profilaxia - drenos, roçados, etc. Vindo Neiva a saber disso durante o jantar, não resistiu à comichão duma pesquisa direta, e a ela se fora enquanto os demais descansavam da viajada no hotel. Eresolveu o problema. Encontrou as anofelinas da espécie perigosa. Tinham o ninho na água depositada pelas chuvas nas bromélias parasitas. Estava liquidado o caso. Regressamos - e no outro dia ordens precisas eram dadas para matar de vez a malária de Iguape em seu derradeiro reduto.

\section{$[\ldots]$}

Nessa noite compreendi o homem e alcancei a força tremenda que se potencializa nos apaixonados da ciência. Pela primeira vez em São Paulo um diretor do Serviço Sanitário esquecia as suas funções burocráticas e fazia ciência pessoalmente à moda de Osvaldo [Cruz].

Este fato ilustra a 'maneira' de Artur Neiva. Não se limita nunca a organizar um serviço; vai ver, cheirar, apalpar; identifica-se com ele, apaixonase, e com o exemplo transmite aos seus auxiliares aquele fervoroso interesse sem o qual todo serviço encrua em catequismo burocrático. Foi assim que remodelou, inteira, a organização sanitária de São Paulo." (Lobato, 1961d, p. 171-3).

\section{Perspectiva dos Pacientes sobre Doença, Tratamento e Cura}

\section{Diferentes significados do adoecer}

Em Urupês, no conto "O engraçado arrependido", temos uma rica e bem-humorada descrição a respeito de um major que estava doente há muito tempo, mas que tomava todos os cuidados para não sucumbir à doença.

“[...] Seu aneurisma, na opinião dos médicos que matavam por alopatia, era coisa grave, de estourar ao menor esforço; mas o precavido velho não tinha pressa de ir-se para melhor, deixando uma vida onde os fados lhe conchegavam tão fofinho, e lá engambelava a doença com um regime ultrametódico. Se o mataria um esforço violento, sossegassem, ele não faria tal esforço.” (Lobato, 1961a, p. 114).

Os médicos, conforme se apresenta no conto, diagnosticaram que a doença do major era grave. Interessante é o trecho irônico, que destaca que os médicos matavam por alopatia. $\mathrm{O}$ autor novamente utiliza-se de sua veia cômica para destacar que o atendimento médico muitas vezes pode causar iatrogenias, e que os pacientes, mesmo assistidos, corriam sérios riscos ao iniciar tratamentos prescritos pelos profissionais.

Ainda estudante, ao mudar-se em São Paulo para novo bairro, "perto do Cambuci", Monteiro Lobato procura meios de conhecer a vizinhança, de se enturmar. Assim, observa-se um engraçadíssimo relato que ele faz sobre a estratégia utilizada para chamar a atenção dos moradores:

"À tarde saí a passeio; percorri logo em 15 minutos todo o meu bairro. Fui à venda prosear com a vendei- 
ra, uma boa italiana moradora aqui há nove anos. Eu havia saído de sobretudo, chapéu duro e luvas, me apoiando na bengala como um convalescente. A minha pose, me fingindo de doente! Adorável! As mulheres da Rua Mazzini me olhavam com curiosidade, os homens com rancor e eu sereno, superior, com ares de milionário em vilegiatura, percorri toda a rua em passo calmo de velho. $\mathrm{Na}$ volta introduzi-me numa rodinha de italianos. [...]" (Lobato, 1961e, p. 140).

O trecho acima mostra que processos mórbidos costumam ajudar na socialização das pessoas, seja por condescendência em relação ao doente, seja por curiosidade com relação à sua condição de saúde.

O conto "O rapto", presente em Cidades Mortas, mostra as possibilidades que o adoecer pode oferecer ao doente e aos seus entes próximos. Em uma pequena cidade, um pai paupérrimo, que vira os filhos violentos saírem de casa, vê-se às voltas com a piedade da comunidade ao tornar-se cego. Os filhos também se reaproximam e pedem perdão, ao observar o novo status do velho.

"Bento dizia:

- Deus dá nozes a quem não tem dentes. Agora que é um corpo só na casa, tanta roupa, até fraque...

Mas os filhos marotos cheiraram de longe a reviravolta da fortuna e bateu-lhes a pacuera do arrependimento. Hoje um, amanhã outro, vieram os três, cabisbaixos e humílimos, implorar perdão ao velho.

Que não perdoará um cego, inda mais pai? Bento perdoou-os e readmitiu-os em casa. A esmola sempre farta havia de dar para todos.

E deu. Nunca daí por diante faltou feijão à panela, nem roupa ao corpo, nem dinheirinho para o resto, inclusive cachaça e fumo.

Milagre! Aquele homem que de olhos perfeitos jamais conseguira coisa alguma na vida além do desprezo público e da pancada dos filhos, recebia agora provas de carinho, gozava certa consideração, fazia-se chefe da casa, respeitado, ouvido - e até temido!". (Lobato, 1961b, p. 236).

A batalha das mães pobres para manter seus filhos na escola, fazendo sacrifícios para que eles não sejam enviados de volta para casa por não seguirem as regras da escola, aparece em "Vidinha Ociosa", $\mathrm{Ci}$ dades Mortas, em que a cada dia o menino é enviado à escola com um pé calçado e o outro descalço, por sofrer de "bicho arruinado".

“- Que doença de pés é essa? Bicho arruinado?

O pequeno baixou a cabeça com acanhamento; depois confessou:

- É “inconomia.”

Compreendi. Como nos Grupos não se admitem crianças de pé no chão, inventaram as mães pobres aquela pia fraude. Um pé vai calçado; o outro, doente de imaginário mal crônico, vai descalço. Um par de botinas dura assim por dois. Quando um pé de botina em uso fica estragado, transfere-se a doença de um pé para outro, e o pé de botina de reserva entra em funções. Dest'arte, guardadas as conveniências, fica o dispêndio cortado pelo meio. Acata-se a lei e guarda-se o cobre.

Benditas sejam as mães engenhosas!".(Lobato, 1961b, p. 24).

\section{Visão dos pacientes sobre suas alternativas de cura}

Em carta a Godofredo Rangel, de 7 de fevereiro de 1912, Lobato comenta sua experiência com relação à cura de diversos males que podem afligir crianças, decorrentes do acompanhamento dos padecimentos de seus filhos. Ele se compara, em termos de atuação e experiência, aos médicos. Observe-se a ironia do trecho final, em que se depreende que os médicos, formados, não costumam conseguir resolver os problemas de saúde com os quais se deparam seus pacientes, e, portanto, talvez essa ciência ainda tenha muito o que aprender.

"Quanto ao teu Caio... Manda-me todos os sintomas que eu o curo.

Idade certa, se mamou leite materno e até quando, que regime está seguindo, há quanto tempo veio a diarreia - consistência, cor, cheiro e acidez (verificada com papel de turnessol), quantas vezes evacua por dia, se chora muito, etc., etc.

Virei médico à força por causa dos filhos, e tenho obtido curas maravilhosas. Em diarreia sou mestre. E como sou 'doutor', todos aqui me procuram e tomam 
meus remédios e saram ou morrem - tal qual como os médicos de verdade." (Lobato, 1961f, p. 326).

Outro trecho interessante se refere à orientação dada por Lobato à Teca, sua irmã, para curas diversas, ou quando ainda não se conhece o mal que aflige o paciente. 0 próprio autor constata que a medicina tradicional convivia com as práticas caseiras de tratamento das doenças, de receitas passadas de geração em geração para a cura dos males. Principalmente nas regiões afastadas das grandes cidades, as receitas caseiras, as folhas e raízes encontradas no mato, e diversos excrementos animais poderiam fazer as vezes de "remédio" (Wissenbach, 1998). Novamente, a ironia perpassa pelo trecho, quando Lobato comenta, de passagem, que bórax é eficiente no combate a baratas, especialmente se for acrescido de bastante açúcar; além disso, ao juntar, no mesmo comentário, alusão a males humanos e ao problema das baratas, observa-se que o autor possuía ampla consciência sobre as questões que podem afetar a saúde das pessoas, já que considerava todos como problema de saúde.

"A camomila dá-se em doses de 4 a 6 glóbulos de 2 em 2 ou 3 em 3 horas aos primeiros sintomas de qualquer doença. É um remédio geral e inicial enquanto não se define a moléstia. Para baratas é muito bom o bórax ou ácido bórico misturado com açúcar e do qual elas são muito gulosas.” (Lobato, 1961g, p. 125).

Foram diversas as viagens da fazenda, onde moravam em 1912, até Taubaté, e dali a São Paulo, sem, no entanto, obter alívio para os males de um de seus filhos. Lobato e a esposa procuram por diversos especialistas para curar a rinite de Edgard, de 2 anos, e retornam à fazenda desencorajados, com a promessa de que, ao tornar-se adulto, isso seria curado. Ao visitar uma prima, encontra um livro de cura por meio de homeopatia, e imediatamente, ele procura pelo capítulo referente ao "nariz".

Leio conjuntos de sintomas. Um deles coincide com os sintomas da rinite do Edgard. Prescrição: 'Mercurius'. Entra a prima. Conto o caso do menino e aquele encontro ali. 'Vale alguma coisa isto de homeopatia?', pergunto, cético. E ela: 'Experimente. Não custa.' Quando saí passei pela farmácia. 'Tem Mercurius?' Tinha. Comprei cinco tostões. [...] Levo para casa. [...] Sem fé nenhuma, dou automaticamente os carocinhos ao Edgard, mais do que mandavam as instruções. Cinco em vez de três. Depois, mais cinco. De noite, mais cinco. No dia seguinte, o milagre: todos os sintomas da rinite haviam desaparecido!... Mas sobreviera uma novidade: purgação nos ouvidos. Cheio de confiança, corro à casa da prima, atrás do livro de capa verde. Procuro 'Ouvidos' e leio esta maravilha: 'Às vezes sobrevém purgação no ouvido por abuso de Mercurius, e nesse caso o remédio é Sulfur.' Vou voando à farmácia. Compro Sulfur. Mais 500 réis. Dou Surfur ao Edgard e pronto - sarou do ouvido! Sarou da Rinite, sarou de tudo! Preço da cura: 100 o réis. Pela alopatia, em troca da não cura: várias consultas médicas, viagem a $\mathrm{S}$. Paulo, drogas insuflantes e aparelho insuflador - e a desesperança." (Lobato, 1961g, p. 133).

Como qualquer paciente que procura alívio para seus males sem conseguir resolvê-los, Lobato era aberto a ouvir e procurar modos alternativos de cura. Ao final do episódio que relata o processo de busca da cura para a rinite de seu filho Edgard, ele mostra pouco ânimo em esgotar as possibilidades de resolver os problemas de saúde apenas contando com a medicina tradicional; e sintetiza: "desesperança".

Esse episódio acaba sendo utilizado como exemplo para não se preocupar demais com problemas cotidianos que podem, às vezes, se resolver sem tanto esforço e desgaste emocional. Em outra carta à irmã Ester (apelidada de Teca), ao referir-se a pessoas conhecidas em comum que padeciam de diversos males, Lobato cita o episódio do filho para mostrar que às vezes grandes problemas podem ser resolvidos inesperadamente, e que a solução pode estar nos lugares menos prováveis.

“[...] A gravíssima rinite do Edgard, que só sararia com a idade, aos 20 anos, sarou com 10 caroços de homeopatia. E assim os grandes males que caem por casa abortam em coisinhas sem importância [...]." (Lobato, 1961h, p. 167).

\section{Considerações Finais}

Analisar a obra de Monteiro Lobato tratou-se de um enorme desafio, tanto pelo seu volume quanto, e principalmente, pela responsabilidade de oferecer 
um novo olhar ao material consagrado pelos inúmeros leitores que o autor veio colecionando em toda sua trajetória, tanto em vida quanto após a sua morte. Conforme já comentado no início do presente texto, não se teve como objetivo esgotar a opinião do autor a respeito dos temas que se relacionavam com saúde. Teve-se a intenção de registrar mais uma faceta desse intrigante autor que, além de escritor, editor, adido comercial e defensor das riquezas deste país, aventurou-se também na arte da pintura, de colecionar amigos, de escrever cartas, e de hipnotizar as crianças com suas histórias (Cavalheiro, 1955).

Já no fim da vida, ele continuava a manter religiosamente em dia a sua correspondência, o que, certamente, nos permitiu conhecer um pouco mais do Lobato pessoa.

“[...] Um pai escreveu-me: 'Com os meus agradecimentos pela cartinha que o senhor mandou em resposta à do meu filho Lindbergh, dou-lhe a notícia de que essa missiva está concorrendo enormemente para a cura do rapaz. Diz ele que ontem foi um dos dias mais felizes de sua vida.." (Lobato, 1961g, p. 350).

\section{Referências}

ANTUNES, J. L. F.; NASCIMENTO, C. B.; NASSI, L. Laboratório de Saúde Pública (1892-1925): cronologia histórica. In: ANTUNES, J. L. F.; NASCIMENTO, C. B.; NASSI, L.; PREGNOLATTO, N. P. (Org.). Instituto Adolfo Lutz: 100 anos do laboratório de saúde pública. São Paulo: Letras \& Letras, 1992. p. 43-87.

BERTOLLI FILHO, C. A gripe espanhola em São Paulo, 1918: epidemia e sociedade. São Paulo: Paz e Terra, 2003.

CAVALHEIRO, E. Monteiro Lobato: vida e obra. São Paulo: Companhia Editora Nacional, 1955.

DUARTE, L. C. Lobato humorista: a construção do humor nas obras infantis de Monteiro Lobato. São Paulo: Unesp, 2006.

LAJOLO, M. Lobato, um Dom Quixote no caminho da leitura. In: . Do mundo da leitura para a leitura do mundo. São Paulo: Ática, 1993. p. 94103.
LAJOLO, M.; CECCANTINI, J. L. (Org.). Monteiro Lobato livro a livro: obra infantil. São Paulo: Unesp: Imprensa Oficial do Estado de São Paulo, 2008.

LIMA, N. T.; HOCHMAN, G. Pouca saúde, muita saúva, os males do Brasil são... discurso médicosanitário e interpretação do país. Ciência \& Saúde Coletiva, Rio de Janeiro, 20oo, v. 5, n. 2, p. 313-332, 2000.

LOBATO, M. Urupês. São Paulo: Brasiliense, 1961a. (Obras completas de Monteiro Lobato, 1).

LOBATO, M. Cidades mortas. São Paulo:

Brasiliense, 1961b. (Obras completas de Monteiro Lobato, 2).

LOBATO, M. Negrinha. São Paulo: Brasiliense, 1961c. (Obras completas de Monteiro Lobato, 3).

LOBATO, M. Mr Slang e o Brasil e Problema vital. São Paulo: Brasiliense, 1961d. (Obras completas de Monteiro Lobato, 8).

LOBATO, M. Literatura do minarete. São Paulo: Brasiliense, 1961e. (Obras completas de Monteiro Lobato, 14).

LOBATO, M. A barca de Gleyre. São Paulo: Brasiliense, 1961f. t. 1. (Obras completas de Monteiro Lobato, 11).

LOBATO, M. A barca de Gleyre. São Paulo: Brasiliense, 1961g. t. 2. (Obras completas de Monteiro Lobato, 12).

LOBATO, M. Cartas escolhidas. São Paulo: Brasiliense, 1961h. t. 1. (Obras completas de Monteiro Lobato, 16).

LOBATO, M. Cartas escolhidas. São Paulo: Brasiliense, 1961i.t. 2. (Obras completas de Monteiro Lobato, 17).

TELAROLLI JÚNIOR, R. Imigração e epidemias no Estado de São Paulo. História, Ciências, Saúde Manguinhos, Rio de Janeiro, v. 3, n. 2, p. 265-283, 1996.

THIELEN, E. V.; SANTOS, R. A. Belisário Penna: notas fotobiográficas. História, Ciências, Saúde Manguinhos, Rio de Janeiro, v. 9, n. 2, p. 387-402, 2002. 
TIN, E. Em busca do "Lobato das cartas": a construção da imagem de Monteiro Lobato diante de seus destinatários. 2007. Tese (Doutorado em Teoria e História Literária) - Universidade Estadual de Campinas, Campinas, 2007.

SHEPPARD, D. S. A literatura médica brasileira sobre a peste branca: 1870-1940. História, Ciências, Saúde - Manguinhos, Rio de Janeiro, v. 8, n. 1, p. 172-192, 2001.

WISSENBACH, M. C. C. Da escravidão à liberdade: dimensões de uma privacidade possível. In: NOVAIS, F. (Org.). História da vida privada no Brasil: república: da belle époque à era do rádio. São Paulo: Companhia das Letras, 1998. v. 3, p. 49-130. 